Preprint of: Lee, WL; Abdullah, KL; Bulgiba, AM and Abidin, IZ. (2013) Prevalence and predictors of patient adherence to health recommendations after acute coronary syndrome: data for targeted interventions? European Journal of Cardiovascular Nursing 12(6): 512-520. DOI: 10.1177/1474515112470056.

Downloaded

http://cnu.sagepub.com/content/early/2013/01/01/1474515112470056.abstract

\title{
Prevalence and predictors of patient adherence to health recommendations after acute coronary syndrome: data for targeted interventions?
}

(Lee, Wan Ling; Abdullah, Khatijah Lim; Bulgiba, Awang Mahmud and Abidin, Imran Zainal)

\section{ABSTRACT}

Background: Poor adherence is a significant nursing and public health concern because it affects patients' quality of life and it compounds disease burden of the growing coronary heart disease population. Promoting optimal patient adherence to cardiac-health enhancing recommendations by healthcare providers can reduce mortality and morbidity risk after ACS.

Aim: This paper sought to examine rates and predictors of patient adherence to health recommendations after acute coronary syndrome (ACS).

Methods: A cross sectional survey of 210 Malaysian patients using consecutive sampling was conducted in early 2009 at a tertiary teaching hospital. The Medical Outcome Study Specific Adherence Scale (MOSSAS) questionnaire was adapted to measure the extent of patient adherence to recalled health recommendations. Logistic regression modelling was applied to determine odds ratio and factors of suboptimal adherence. 
Results: The suboptimal adherence rate was prevalent at $65.2 \%(95 \% \mathrm{Cl}: 58.8 \%$ to $71.7 \%$ ). The recalled of recommendation rates varied from $38.1 \%-95.3 \%$ while the adherence rates varied from $22.1 \%$ to $95.1 \%$ across the six aspects of health recommendation namely: medication taking, dietary modification, regular physical exercise, stress reduction, gathering social support and avoidance of substances abuse. There were higher odds of suboptimal adherence among those who had to adhere to more than three aspects of recommendations, active smokers and the Malay ethnic race.

Conclusion: Monitoring of patient recall and adherence rate may provide information on the effectiveness of patient care management and outcomes. Identifying patients with higher risk for poor adherence is recommended for more targeted interventions.

KEY WORDS: patient adherence; compliance; acute coronary syndrome; cardiac rehabilitation; secondary prevention

\section{Corresponding author:}

\section{Lee Wan Ling}

Department of Nursing Science, Faculty of Medicine University of Malaya 50603 Kuala Lumpur

Malaysia

Email: wllee@um.edu.my 


\section{Introduction}

Acute coronary syndrome (ACS) accounts for a large portion of the morbidity and mortality of patients with coronary heart disease (CHD), which remains the leading cause of death and disease worldwide [1]. The incidence of ACS admission in Malaysia was reported at 47.1 per 100,000 populations in 2006 [2]. Cardiovascular mortality risk in non adherent ACS survivors is comparable to those untreated patients who risk a death rate of $5 \%$ per year following a first myocardial infarction and increasing with recurrence [3]. Cardiachealth enhancing recommendations prescribed to reduce cardiovascular risk are efficacious [4, 5], but the outcome is dependent on patient adherence [6]. Studies exploring patient adherence to a cluster of cardiac health enhancing behaviours are few $[7,8]$ and more are needed since poor adherence is a significant concern in the nursing and public health fields. Poor adherence affects patient's quality of life and compounds disease burden of the growing CHD population. It attenuates treatment efficacy resulting in suboptimal health outcomes. It also contributes to wasting of scarce healthcare resources and an escalation in healthcare cost for the treatment of disease complications [8-10].

Adherence is a dynamic process requiring regular screening or monitoring $[9,11]$ as adherers are vulnerable to relapse from time to time especially factors affecting their adherence changes. Reviews had observed that no constant variable was found to be predictive of adherence $[8,12-17]$. The results observed were influenced by the varying differences in sample, regimen types, and measurement used in the primary studies. Such studies from Asian population 
were few; thus, this study was conducted in Malaysia with intention to add the socio-cultural perspective to pool of empirical evidence.

It is not possible to eliminate problems of poor adherence completely as evidenced by prevailing low uptake and adherence to cardiac rehabilitation or secondary prevention programme $[15,18,19]$. A regular screening measure will facilitates prompt identification of suboptimal adherence to improve or remediate it [11]. Prior to embarking on any endeavours to improve better adherence, one needs to determine the adherence rate as a proxy indicator to gauge efficacy of a programme and to estimate severity of adherence problem for more cost effective specific targeted measures. Thus, the aim of this study was to examine (1) patient adherence to health recommendations that they recalled; and (2) prevalence and predictors of adherence among survivors of ACS.

\section{METHODS}

\subsection{Design and Sampling}

This was a cross sectional survey conducted from $1^{\text {st }}$ January to $31^{\text {st }}$ March 2009. Patients were consecutively sampled from a cardiac clinic and the wards of a large public tertiary teaching hospital in Kuala Lumpur, Malaysia. Only stable patients with indexed diagnoses of ACS less than 12 months during study were recruited in order to minimize recall bias and time-dependent confounders. Patients with concomitant depression were excluded in view of evidence that showed depression was associated with poor adherence [20, 21]. 
Sample size was based on reported non-adherence rates of $30 \%$ in unexposed patients, odds ratio of $2.5[8,22]$, power of $80 \%$ and alpha of $5 \%$. Assuming a 1:1 ratio between exposed and unexposed groups, this gave a total sample size of 164 . We factored in an additional $20 \%$ non-response rate to account for missing values which provided an eventual total of 197.

\subsection{Data collection}

Given the accuracy required for this type of study and that there is no gold standard method available, patient-reported measures were chosen for its versatility, practicality and acceptability by the patients. Many patients came to hospital alone or with someone who was unaware of their adherence behaviour precluded the use of collateral rating. Clinical or physiological measures such as serum cholesterol or blood pressure can be influenced by various confounding factors (e.g. presence of several co-existing chronic diseases and its severity, varying individual or genetic responses to drug and disease); thus rendering them unreliable measures of adherence.

In view of possible negative patient perception of the word "adherence" or "compliance", permissive statements such as "We are interested to know from your experience which health care seems to be more difficult or easier to do" prefaced the questionnaire. Questionnaire was interview-administered only upon request of the patients. Other measures to encourage honest responses from patients included informing them that the researcher had no direct involvement with their care, using code to label the questionnaire, adopting non-judgmental 
attitudes throughout the interaction, reassuring them of confidentiality and the purpose of the study was not to seek personal weaknesses but to identify shortcomings in current care.

\subsection{Ethical considerations}

Study was carried out after obtaining approval from an Institutional Review Board (reference no: 691.20) and was conformed to the principles outlined in the Declaration of Helsinki. Informed consent from patients was obtained prior to administering the questionnaire.

\subsection{Measure of adherence - validity and reliability}

The Medical Outcome Study Specific Adherence Scale (MOSSAS) that were specific to patients with heart disease was used to examine adherence to wide range of behaviour [23-25]. Content validity of MOSSAS was checked with the cardiologist and nurse specialist in the Coronary Care Unit. An item pertaining to adherence to cardiac rehabilitation was excluded because the service was not fully established during data collection. The questionnaire was translated into three major languages used in Malaysia namely Malay, Mandarin and Tamil. We did not perform forward-backward translation since this method is arguably based on expert opinion instead of scientific evidence [26]. The original and translated questionnaires were verified with two bilingual literate patients for each language. Items in source version of MOSASS were straightforward and no discrepancies of translation highlighted. Based on pilot results of 20 patients, all 
items were retained but questionnaire was slightly reformatted for a more reader friendly layout.

Two parallel lists to differentiate adherence behaviours from health behaviours was administered: (1) a list requesting patients to recall health recommendations they received by responding with a "Yes" or "No"; and (2) 9item MOSSAS asking patients to rate how often they performed those recommended behaviours in the past four weeks on a six-point scale in which $1=$ "none", $2=$ "rarely", $3=$ "sometime", $4=$ "a lot of time", $5=$ "most of the time" and $6=$ "all the time". We defined adherence as "the extent to which patients follow the instructions they are given for prescribed treatment" [27]. Thus, only reported behaviours that corresponded with recommendations recalled by patients were scored from 1 to 6 according to scale and was checked for internal consistency. Cronbach's alpha coefficient was 0.58 in compared to studies predominated by Caucasians sample in Spernak et al. [25], Fogel [24] and Kravitz et al. [23] that reported $0.63,0.77$ and 0.53 respectively. The modest internal consistency was accepted since the items measured were heterogeneous.

\subsection{Data analysis}

Data were analyzed using the SPSS version 16 software. The nine items of MOSSAS that were recalled and adhered by patients were categorized into six aspects of health recommendations (Table 1) and were descriptively analysed for recalled rates and adherence rates (Table 2). In each patient, adherence scores for behaviours that corresponded with recommendations recalled was summed 
and averaged to compute overall adherence score. Patients with overall adherence score of less than 5 were suboptimal adherers indicating they performed the recommended behaviours less than 'most of time' on the average. This proportion of suboptimal adherers was used to calculate prevalence of suboptimal adherence.

Chi-squared $\left(X^{2}\right)$ tests were used to determine crude associations of suboptimal adherence in relation to 11 predictor variables of interest listed in Table 3. Multiple logistic regression using the Hosmer-Lemeshow approach (backward elimination) was used to account for confounding and to look for independent predictors. P-value of $<0.25$ was used for entry into the model. The difference in -2 log likelihood ratio between the full and nested models was compared with chi-square values with the appropriate degrees of freedom. Results were reported as odds ratios with $95 \%$ confidence intervals $(\mathrm{Cl})$. All statistical tests were performed with a significance level of 0.05 .

\section{Results}

\subsection{Sample characteristics}

Response rate was $99.5 \%(\mathrm{~N}=210)$ with only one respondent was excluded from further analyses due to non-response to MOSSAS. Sample characteristics are summarized in Table 3. The high numbers of non-employed patients $(n=135,64.3 \%)$ can be attributed to $138(65.7 \%)$ patients who were at least 55 years - the retirement age in Malaysia at the time of study. All reported smokers and drinkers prior to the recent ACS were male patients. Twenty one 
(72\%) out of 29 active smokers was younger than 60 years. The median duration of adherence to the recommended lifestyle changes following ACS was 18 weeks with an inter-quartile range of 7 to 31 weeks.

\subsection{Recollection and adherence to each aspect of health recommendations}

Table 2 summarized the recalled rates in descending order. Two categories of optimal adherence rates were based on proportion of patients with adherence scores $\geq 5$ and of 6 on the MOSSAS scale. Fifty five (26.2\%) patients had support from family and/or friends on a frequent basis even without being

recommended by health care providers. Seventy one (33.8\%) patients had recalled and adhered to at least five aspects of the recommendations. Sixteen patients (37.2\%) who were alcohol drinkers reported quitting the habit completely.

\subsection{Prevalence and factors of suboptimal adherence}

The prevalence of sub-optimal adherence in Malaysian patients following ACS was $65.2 \%$ (95\% Cl $58.8 \%, 71.7 \%)$. The proportion and odds ratio of suboptimal adherers were examined according to various patient characteristics (Table 3). Table 4 lists factors that are independently associated with suboptimal adherence. Variables which did not contribute significantly to the final multiple logistic model were age, gender, marital status, educational level, employment status, indexed diagnosis of ACS and alcoholic drinking status. We were not able to eliminate ethnic variable from the model, so the final model includes major race, number of behavioural changes and smoking status as independent predictors of sub-optimal adherence. A test of the full model against a constant 
only model was statistically significant, indicating that the predictors were reliably distinguished between suboptimal and optimal (chi-square 58.048, $p<0.001$ with df 4). No interactions were found between race, types of behavioural and smoking status. The odds of suboptimal adherence were higher in those who had to adhere to four or more types of health recommendations (OR $6.03 ; 95 \% \mathrm{Cl}$ $3.02,12.05)$ and those who still actively smoked (OR 14.74; 95\% Cl 1.86, 117.07). In comparison to the Indian race, the Malays had a higher odds ratio of suboptimal adherence at $1.67(95 \% \mathrm{Cl} 0.77,3.63)$ while inversely, the Chinese have a lower odds ratio of $0.63(95 \% \mathrm{Cl} 0.27,1.541)$.

\section{DISCUSSION}

This study showed a high prevalence of suboptimal adherence with varied recalled and adherence rates and found three predictors of adherence.

\subsection{Recalled rates}

The descending recalled rates of health recommendations depicted in Table 2 was comparable to one similar study [23]. Wide variations in recalled rates can be attributed to several factors, including patients' tendency to forget a proportion of information especially when presented in large amounts [28, 29]. Hospital stay with a median of four to five days for patients admitted with ACS [30] limited the opportunity to support, educate, and counsel patients in a timely and unhurried manner, particularly in promoting adherence to a wide range of lifestyle modifications. The recalled rates can be a proxy indicator for gauging how effective the delivery of information to patients. Acquisition of knowledge or 
health literacy on cardiovascular risk reduction measures was associated with and a precursor to adherence [16, 29]. Data on recalled rates also provides information on areas of need. For instance, gathering of social support is an area for potential work since many patients in this study reported performing it without receiving the recommendation to do so. More so, studies had reported that favourable social support can encourage adherence behaviour [31, 32]. Low recalled rates with corresponding low adherence rates in stress reduction indicating an area requiring further research. A qualitative inquiry to obtain the patient's perspective on stress management after ACS is recommended in order to uncover methods in countering stress that is suited to the patient type.

\subsection{Adherence rates}

When considering optimal adherence in taking medication based on a scale of 6 ("all the time'), we found the rate of $19 \%$ was lower than $91.3 \%$ reported by a study conducted two decades ago in 1986 at three large cities of United States by Kravitz et al. using the same scale [23]. Differences in culture, changes in population socioeconomic profile related to inflation and demographic characteristics of this study such as a higher proportion of male, married respondents, lower educational and lower income levels are possible reasons to explain the aforementioned difference in medication adherence rates. However, the gap in rates was reduced if we used lower criteria to define optimal medication adherence such as using a scale of 5 ("most of time") instead of 6 . It is reasonable to use a scale of 5 out of 6 as a cutoff point based on a study that 
defined medication adherence as achieving at least $80 \%$ days of correct number of pills taken as measured by the Medication Event Monitoring System (MES). MES is able to record the date and time whenever the medication cap is opened [33]. Besides, the cutoff point to classify optimal medication adherence is arbitrary and varied across studies depending on various factors, including types of instruments used. Thus, the medication taking adherence rate in this study was calculated at $62.6 \%$ based on a scale of 5 . This rate was comparable to reviews and studies which showed that medication adherence rates tended to converge around $50 \%$ in populations with chronic diseases $[9,34]$. With this rate, medication adherence was higher than adherence rates of dietary modification, regular exercise, stress reduction and gathering of social support that were in descending order, respectively. This observation was consistent with other previous studies [23, 24, 35-37].

The low rate of exercise adherence was also consistent with the findings of other studies [7, 23]. The less than ideal rate of medication and exercise adherence observed in this study could be attributed to lack of enrolment of study participants in a cardiac rehabilitation programme, which has been associated with improved adherence rate [38]. The cardiac rehabilitation programme, especially the exercise component, was not fully established in the study setting during the data collection period. Besides factor of programme access, the influence of cultural is another plausible reason to low exercise adherence rates highlighted by Galdas et al. [39] but the assumption need more research to provide further support. 
Despite high recall rates, adherence to smoking cessation and alcohol limitation was less than ideal at $51.9 \%$ and $69 \%$ respectively, but it was higher than the respective rate of $9.6 \%$ and $40 \%$ reported by Kravitz and colleagues [23]. The observed differences can be attributed to the changing trends in the management of $\mathrm{CHD}$ that are moving towards promoting smoking cessation more intensively and the prohibition of alcohol in Islam, the religion of the Malays.

\subsection{Prevalence of adherence}

In this study population, we obtained a suboptimal adherence of $65.2 \%$ which was more prevalent compared to $23.4 \%$ reported in a meta-analysis of 129 studies in patients with cardiovascular diseases with varying treatment regimes [6]. It was also higher than the $56 \%$ reported by Aziz and Ibrahim [40] who examined medication adherence among Malaysians. Variation in patient management and the tools used to measure adherence also account for the difference observed. These results supported the findings that adherence to a variety of lifestyles or behavioural changes was relatively harder than adherent behaviour that was solely focused on medication taking [29].

\subsection{Factors of adherence}

We found three major factors influencing adherence which were namely smoking status, number of adherence behaviours and ethnicity. We found higher odds of suboptimal adherence in active smokers, which confirmed previous observations [36, 41]. A review by Taylor and colleagues [17] reported that 3 out 10 studies had reported higher odds of poor adherence among active smokers. 
For smokers, the stressful experience of nicotine withdrawal could pose difficulties for them to concentrate efforts on lifestyle or behavioural change. We also found higher odds of suboptimal adherence among patients who had to adhere to more than three types of recommendations. The more types of change required, the more it demanded from patients to acquire adherence skills or a capacity to make behavioural or lifestyle changes $[9,12,42,43]$. The difference in the odds of suboptimal adherence among major races in Malaysia is an interesting new finding as there is no study to describe such an association. It may be speculated that being a multi ethnic and multi religious country, the different health behaviours and practices among the major races in Malaysia may have influenced the adherence rates reported in this study. It has also been noted that religious beliefs and practices can promote an optimistic view towards daily experiences and religion is most used for coping or adaptation in any stressful situation [44]. However, a study using mixed method approach with a larger sample size is needed to provide more support and explanation to this observation in view that those behaviours could be influenced by cultural belief [45] and future strategies in tackling suboptimal adherence required healthcare providers to be culturally competent $[39,46]$.

In this study, we found that the age did not strongly influence the multivariable model, although a review reported six studies that found an association between age and adherence, but the direction of the relationship was not consistent [17]. We also found no association between socioeconomic factors with suboptimal adherence. Those observations could be attributed to study site 
and sample characteristics. This study was conducted in a public hospital which charges lower rates than private hospitals and accords free medical benefits to government retirees. When patients have access to healthcare, it can enhance their adherence [9]. Associations between duration and adherence behaviours were not established. Adherence duration (less than a year following the ACS event) may be too short to be predictive of adherence patterns across time. This result also suggested that assessing patient adherence can be carried out at any time but once yearly. The absence of a relationship between types of ACS and adherence behaviour may be moderated by the patient's objective perception of illness severity [16]. Many did not experience post ACS symptoms that were severe enough to cause marked limitations to the extent of requiring substantial adjustment of their lives.

\subsection{Limitations of the study}

It is well documented that adherence is a difficult construct to measure accurately, particularly in adherence to a wide range of behaviours. Some degree of recall biases and social desirability response biases are inherent with the survey approach using patient-reported measure. Other limitations due to time constraints include the concurrent, cross-sectional nature of the study design that could only allow measurements of absolute levels rather than measuring changes in adherence behaviours. The sampling was confined to a single site, therefore, limiting the generalization of findings to populations with different socioeconomic topology. However, the characteristics of the patients were 
congruent with age, gender and ethnic prevalence of $\mathrm{CHD}$ in Malaysia as observed in a national registry report [30].

\subsection{Conclusion and recommendations}

This study proposes that health care professionals should be more vigilant without prejudice to screen adherence levels in patients with higher risk of poor adherence including those who have to adhere to complex regimes which require change in many behaviours or lifestyles. More so in active smokers especially in view of a reported $36 \%$ reduction in crude relative risk of mortality when they quit smoking - a benefit that is comparable to the use of statins in lowering cholesterol [47]. Problems of suboptimal adherence are here to stay. Stratifying patients based on their adherence level enables early targeted interventions accordingly [48]. Early achievement of optimal adherence is desirable as it could be predictive of long term adherence [7]. Further research is required to explore this assumption. Targeted approach based on adherence level is becoming a practical proposition for an effective management of poor or non adherent patients in view of the increasing scarcity of health care resources, the rising prevalence of chronic diseases and the cost-saving of adherence promoting intervention outweigh cost of treating complication resulted from poor adherence [10].

The results also suggest that suboptimal adherence is prevalent. Regular monitoring of patient adherence rates as well as recalled rates can provide information on the effectiveness of patient care management and outcomes. A 
prospective study with a longer duration with repeated measures of adherence is recommended for more accurate assessments of adherence reflecting both patient and treatment or care outcomes. The difference in the odds of suboptimal adherence among major races in Malaysia indicated a need to address the importance of having culturally competent healthcare providers.

\section{Acknowledgements:}

The research project is supported by University of Malaya Research Grant (RG034/09). The authors would like to thanks Prof. Dr. Leslie Martin for recommending MOSSAS, Prof. Dr. Kulenthran Arumugam for earlier statistical advice, Prof. Dr Kader Parahoo for review and all of the patients who participated in this study.

\section{Declaration of conflicting interests:}

None declared.

\section{References}

[1] WHO. The global burden of disease: 2004 update. Geneva 2008.

[2] Wan Azman WA, Sim K-H. Annual Report of the NCVD-ACS Registry Malaysia 2006. Kuala Lumpur: National Cardiovascular Disease Database; 2006.

[3] Law MR, Watt HC, Wald NJ. The underlying risk of death after myocardial infarction in absence of treatment. Archives of Internal Medicine. 2002;162:2405-10.

[4] Jolliffe JA, Rees K, Taylor RS, Thompson D, Oldridge N, Ebrahim S. Exercise-based rehabilitation for coronary heart disease (Review). Cochrane Database of Systematic Reviews. 2001.

[5] Shepherd CW, While AE. Cardiac rehabilitation and quality of life: A systematic review. International Journal of Nursing Studies. 2011. 
[6] DiMatteo MR, Giordani PJ, Lepper HS, Croghan TW. Patient Adherence and Medical Treatment Outcomes: A Meta-Analysis. Medical care. 2002;40:794-811.

[7] Burke LE, Dunbar-Jacob JM, Hill MN. Compliance with cardiovascular disease prevention strategies: a review of the research. Annals Of Behavioral Medicine: A Publication Of The Society Of Behavioral Medicine. 1997;19:239-63.

[8] DiMatteo MR. Variations in Patient Adherence to Medical Recommendations: A Quantitative Review Of 50 Years Of Research. Medical Care. 2004;42:200-9.

[9] Sabaté E. Adherence to long-term therapies: evidence for action. Geneva: World Health Organization; 2003.

[10] Wiegand PN, Wertheimer Al. An economic evaluation of anticipated costs and savings of a behavior change intervention to enhance medication adherence. Pharmacy Practice (18863655). 2008;6:68-73.

[11] Sanderson BK, Southard D, Oldridge N. Outcomes Evaluation in Cardiac Rehabilitation/Secondary Prevention Programs: Improving patient care and program effectiveness Journal of Cardiopulmonary Rehabilitation. 2004;24:68-79.

[12] Vermeire E, Hearnshaw H, Van Royen P, Denekens J. Patient adherence to treatment: three decades of research. A comprehensive review. Journal of Clinical Pharmacy and Therapeutics. 2001;26:331 \pm 42 .

[13] Cooper AF, Jackson G, Weinman J, Horne R. Factors associated with cardiac rehabilitation attendance: a systematic review of the literature. Clinical Rehabilitation. 2002;16:541-52.

[14] Jackson L, Leclerc J, Erskine Y, Linden W. Getting the most out of cardiac rehabilitation: a review of referral and adherence predictors. Heart. 2005;91:10-4.

[15] Beswick AD, Rees K, Taylor FC, Griebsch I, Taylor RS, Victory J, et al. Improving uptake and adherence in cardiac rehabilitation: literature review. Journal of Advanced Nursing. 2005;49:538-55.

[16] DiMatteo MR, Haskard KB, Williams SL. Health belief, disease severity and patient adherence: a meta analysis. Medical Care. 2007;45:521-8.

[17] Taylor GH, Wilson SL, Sharp J. Medical, Psychological, and Sociodemographic Factors Associated With Adherence to Cardiac Rehabilitation Programs: A Systematic Review. Journal of Cardiovascular Nursing. 2011;26:202-9.

[18] Davies P, Taylor F, Beswick A, Wise F, Moxham T, Rees K, et al. Promoting patient uptake and adherence in cardiac rehabilitation. Cochrane Database of Systematic Reviews 2010.

[19] Arena R, Williams M, Forman DE, Cahalin LP, Coke L, Myers J, et al. Increasing Referral and Participation Rates to Outpatient Cardiac Rehabilitation: The Valuable Role of Healthcare Professionals in the Inpatient and Home Health Settings: A Science Advisory From the American Heart Association. Circulation2012.

[20] Kronish IM, Rieckmann N, Halm EA, Shimbo D, Vorchheimer D, Haas DC, et al. Persistent Depression Affects Adherence to Secondary Prevention Behaviors after acute cocornary syndromes. journal of general internal medicine 2006;21:1178-83.

[21] Aggarwal BL. Lifestyle and Psychosocial Risk Factors Predict Non-adherence to Medication. Annals of Behavioral Medicine. 2010;40:228-33. 
[22] Sanderson BK, Phillips MM, Gerald L, DiLillo V, Bittner V. Factors Associated With the Failure of Patients to Complete Cardiac Rehabilitation for Medical and Nonmedical Reasons. Journal of Cardiopulmonary Rehabilitation July/August. 2003;23:281-9.

[23] Kravitz RL, Hays RD, Sherbourne CD, DiMatteo MR, Rogers WH, Ordway L, et al. Recalled of recommendations and adherence to advice among patients with chronic medical conditions. Archives of Internal Medicine. 1993;153:1869-78.

[24] Fogel J. Quality of life in physical health domains predicts adherence among myocardial infarction patients even after adjusting for depressive symptoms. Journal of Psychosomatic Research. 2004;56:75-82.

[25] Spernak S, Moore P, Hamm L. Depression, constructive thinking and patient satisfaction in cardiac treatment adherence. Psychology, Health \& Medicine. 2007;12:172-89.

[26] Swaine-Verdier A, Doward LC, Hagell P, Thorsen H, McKenna SP. Adapting Quality of Life Instruments Value in Health 2004;7:S27-S30.

[27] Haynes RB, Ackloo E, Sahota N, McDonald HP, Yao X. Interventions for enhancing medication adherence (Review). Cochrane Database of Systematic Reviews. 2008.

[28] Flocke SA, Stange KC. Direct observation and patient recall of health behavior advice Preventive Medicine. 2004;38:343-9.

[29] Martin LR, Summer LW, Haskard KB, DiMatteo MR. The challenge of patient adherence. Therapeutics and Clinical Risk Management. 2005;1:189-99.

[30] Wan Azman WA, Sim K-H. Annual Report of the Acute Coronary Syndrome (ACS) Registry 2007 \& 2008. Kuala Lumpur: National Cardiovascular Disease Database; 2010.

[31] DiMatteo MR. Social support and patient adherence to medical treatment: a meta-analysis. Health Psychology. 2004;23:207-18.

[32] Molloy G, Perkinsporras L, Bhattacharyya M, Strike P, Steptoe A. Practical support predicts medication adherence and attendance at cardiac rehabilitation following acute coronary syndrome. Journal of Psychosomatic Research. 2008;65:581-6.

[33] Rieckmann N, Gerin W, Kronish IM, Burg MM, Chaplin WF, Kong G, et al. Course of Depressive Symptoms and Medication Adherence After Acute Coronary SyndromesAn Electronic Medication Monitoring Study. Journal of the American College of Cardiology. 2006;48:2218-22.

[34] Kulkarni S, Alexander K, Lytle B, Heiss G, Peterson E. Long-term adherence with cardiovascular drug regimens. American Heart Journal. 2006;151:185-91.

[35] Leong J, Molassiotis A, Marsh H. Adherence to health recommendations after a cardiac rehabilitation programme in post-myocardial infarction patients: the role of health beliefs, locus of control and psychological status. Clinical Effectiveness in Nursing 2004;8:26-38.

[36] Decker C, Homaa A, Moreng KL, Maddox TM, Reid KJ, Jones PG, et al. Risk factor management after myocardial infarction: reported adherence and outcomes. American Heart Journal. 2009:1-7.

[37] Salamonson Y, Everett B, Davidson P, Andrew S. Magnitude of change in cardiac healthenhancing behaviours 6 months following an acute myocardial infarction. European Journal of Cardiovascular Nursing. 2007;6:66-71. 
[38] Shah ND, Dunlay SM, Ting HH, Montori VM, Thomas RJ, Wagie AE, et al. Long-term Medication Adherence after Myocardial Infarction: Experience of a Community. The American Journal of Medicine. 2009.

[39] Galdas PM, Ratner PA, Oliffe JL. A narrative review of South Asian patients' experiences of cardiac rehabilitation. Journal Of Clinical Nursing. 2012;21:149-59.

[40] Aziz AMA, Ibrahim MIM. Medication Noncompliance - A thriving problem. Medical Journal of Malaysia. 1999;54:192-9.

[41] Gapp O, Schweikert B, Meisinger C, Holle R. Disease management programmes for patients with coronary heart disease-An empirical study of German programmes. Health Policy. 2008;88:176-85.

[42] Ockene IS, Hayman LL, Pasternak RC, Schron E, Dunbar-Jacob J. Task Force \#4-Adherence Issues and Behavior Changes: Achieving a Long-Term Solution. Journal of American College of Cardiology. 2002;40:579-651.

[43] Choudhry NK, Fischer MA, Avorn J, Liberman JN, Schneeweiss S, Pakes J, et al. The Implications of Therapeutic Complexity on Adherence to Cardiovascular Medications. Archives of Internal Medicine. 2011.

[44] Koenig HG, Larson DB. Religion and mental health: evidence for an association. International Review of Psychiatry. 2001;13:67-78.

[45] Chyun DA, Amend AM, Newlin K, Langerman S, Melkus GD. Coronary Heart Disease Prevention and Lifestyle Interventions- Cultural Influences. Journal of Cardiovascular Nursing. 2003;18:302-18.

[46] Davidson PM, Gholizadeh L, Haghshenas A, Rotem A, DiGiacomo M, Eisenbruch M, et al. A review of the cultural competence view of cardiac rehabilitation. Journal Of Clinical Nursing. 2010;19:1335-42.

[47] Critchley JA, Capewell S. Mortality risk reduction associated with smoking cessation in patients with coronary heart disease: A systematic review. Journal of American Medical Association 2003;209:86-97.

[48] Turpin RS, Simmons JB, Lew JF, Alexander CM, Dupee MA, Kavanagh P, et al. Improving Treatment Regimen Adherence in Coronary Heart Disease by Targeting Patient Types. Disease Management Outcomes. 2004;12:377-83. 
Table 1 Specific adherence items in The Medical Outcome Study Specific Adherence Scale (MOSSAS)

\begin{tabular}{lll}
$\begin{array}{l}\text { Six aspects of health } \\
\text { recommendations }\end{array}$ & The nine- item statements \\
\hline Medication taking & 1. I have taken medication as prescribed by doctor. \\
& 2. $\begin{array}{l}\text { I have carried supply of my medicines when outstation or } \\
\text { outside my home. }\end{array}$ \\
Dietary modification & 3. I have followed a low fat or weight loss diet. \\
Regular exercise & 4. I have exercised regularly. \\
Stress reduction & 5. I have cut down on stress in my life. \\
& 6. I have used relaxation method(s) \\
Gathering support & 7. I have socialized more with family, relatives, friends and others. \\
Avoidance of & 8. I have stopped smoking. \\
substance abuse & 9. I have cut down on the alcohol that I drink.
\end{tabular}


Table 2 Recalled and Adherence Rates to Each Aspect of Health

Recommendations

\begin{tabular}{|c|c|c|c|c|c|c|}
\hline \multirow[t]{3}{*}{ Health Recommendations } & \multirow{2}{*}{\multicolumn{2}{|c|}{$\begin{array}{l}\text { Recalled rate } \\
(\mathrm{N}=210)\end{array}$}} & \multicolumn{4}{|c|}{$\begin{array}{l}\text { Adherence rate }(\%) \\
\mathrm{N}_{2} \%=\left(\mathrm{n}_{2} / \mathrm{n}_{1} \times 100\right) \\
\mathrm{N}_{3} \%=\left(\mathrm{n}_{3} / \mathrm{n}_{1} \times 100\right)\end{array}$} \\
\hline & & & \multirow{2}{*}{\multicolumn{2}{|c|}{$\begin{array}{c}\text { Adherence score } \geq 5 \\
\mathrm{n}_{2} \quad\left(\mathrm{~N}_{2} \%\right)\end{array}$}} & \multirow{2}{*}{\multicolumn{2}{|c|}{$\begin{array}{c}\text { Adherence score }=6 \\
\mathrm{n}_{3} \quad\left(\mathrm{~N}_{3} \%\right)\end{array}$}} \\
\hline & $\mathrm{N}_{1}$ & (\%) & & & & \\
\hline \multicolumn{7}{|l|}{ 1. Avoidance of substance } \\
\hline a. Alcohol intake $(n=43)$ & 41 & $(95.3 \%)$ & 28 & $(68.3 \%)$ & 15 & $(36.6 \%)$ \\
\hline b. Smoking $(\mathrm{n}=58)$ & 54 & (93.1\%) & - & & 27 & (50.0\%) \\
\hline \multicolumn{7}{|l|}{ 2. Medication taking } \\
\hline a. Take prescribed medication & 163 & $(77.6 \%)$ & 102 & $(62.6 \%)$ & 31 & $(19 \%)$ \\
\hline b. Carry medicine supply & 162 & $(77.1 \%)$ & 154 & $(95.1 \%)$ & 136 & $(84 \%)$ \\
\hline 3. Diet modification & 147 & $(70.0 \%)$ & 71 & $(48.3 \%)$ & 13 & $(8.8 \%)$ \\
\hline 4. Regular exercise & 129 & $(61.4 \%)$ & 39 & $(30.2 \%)$ & 17 & $(13.2 \%)$ \\
\hline \multicolumn{7}{|l|}{ 5. Stress reduction } \\
\hline a. Cut down on stress & 103 & $(49.0 \%)$ & 39 & $(37.9 \%)$ & 3 & $(2.9 \%)$ \\
\hline b. Use of relaxation methods & 86 & $(40.9 \%)$ & 19 & $(22.1 \%)$ & 5 & $(5.8 \%)$ \\
\hline 6. Gathering social support & 80 & $(38.1 \%)$ & 42 & (52.5\%) & 8 & (10.0\%) \\
\hline
\end{tabular}

Adherence rates were based on adherent behaviours that corresponded with health recommendations recalled by patients.

Adherence score of 5 corresponded on the MOSSAS scale of 5 ("most of the time") and score of 6 to scale of 6 ("all the time"). 
Table 3 Characteristics of the 210 respondents in relation to adherence status

\begin{tabular}{|c|c|c|c|c|c|c|c|c|c|}
\hline \multirow{3}{*}{ Characteristic } & \multirow{3}{*}{$\mathbf{N}$} & \multirow{3}{*}{$(\%)$} & \multicolumn{4}{|c|}{ Adherence status } & \multicolumn{3}{|c|}{ Unadjusted odds ratio } \\
\hline & & & \multicolumn{2}{|c|}{ Optimal } & \multicolumn{2}{|c|}{ Suboptimal } & \multirow{2}{*}{\multicolumn{2}{|c|}{$\begin{array}{l}\text { of suboptimal } \\
\text { adherence }(95 \% \mathrm{Cl})\end{array}$}} & \multirow{2}{*}{$\begin{array}{l}X^{2} p- \\
\text { value }\end{array}$} \\
\hline & & & n1 & (\%) & n2 & (\%) & & & \\
\hline Total sample & & 10 & 73 & (34.8) & 137 & $(65.2)$ & & & \\
\hline \multicolumn{10}{|l|}{ 1. Age group } \\
\hline$<60$ years & 102 & $(48.6)$ & 22 & $(21.6)$ & 80 & $(78.4)$ & 3.25 & $(1.78,5.96)$ & $<0.001^{*}$ \\
\hline$\geq 60$ years & 108 & $(51.4)$ & 51 & $(47.2)$ & 57 & $(52.8)$ & 1 & & \\
\hline
\end{tabular}

2. Gender

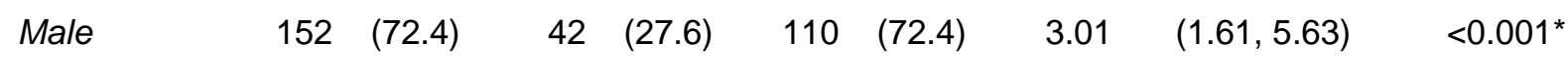

(average 58.94 years, SD 10.050)

$\begin{array}{lllllll}\text { Female } & 58 & (27.6) & 31 & (53.4) & 27 & (46.6)\end{array}$

(average 63.89 years, SD 10.07)

3. Marital status

$\begin{array}{llllllllll}\begin{array}{l}\text { Living with } \\ \text { spouse }\end{array} & 169 & (80.5) & 52 & (30.8) & 117 & (69.2) & 2.36 & (1.18,4.73) & 0.01^{*} \\ \begin{array}{l}\text { Not living } \\ \text { with spouse }\end{array} & 41 & (19.5) & 21 & (51.2) & 20 & (48.8) & 1 & \end{array}$

4. Major race $\ddagger$

$\begin{array}{lcllllllll}\text { Malay } & 84 & (40.0) & 24 & (28.6) & 60 & (71.4) & 1.38 & (0.71,2.71) & 0.083 \\ \text { Chinese } & 48 & (22.8) & 23 & (47.9) & 25 & (52.1) & 0.60 & (0.29,1.26) & \\ \text { Indian } & 73 & (34.8) & 26 & (35.6) & 47 & (64.4) & 1 & & \\ \text { Others } & 5 & (2.4) & & & & & & \end{array}$

5. Education level

$\begin{array}{lrlllllcll}\text { Lower } & 85 & (40.5) & 35 & (41.2) & 50 & (58.8) & 1 & & 0.107 \\ \text { Upper } & 125 & (59.5) & 38 & (30.4) & 87 & (69.6) & 1.60 & (0.90,2.85) & \end{array}$

6. Employment status

$\begin{array}{lrllllllll}\text { Employed } & 75 & (35.7) & 19 & (25.3) & 56 & (74.7) & 1.97 & (1.05,3.67) & 0.032^{*} \\ \begin{array}{l}\text { Non- } \\ \text { employed }\end{array} & 135 & (64.3) & 54 & (40.0) & 81 & (60.0) & 1 & \end{array}$

7. Economic status (income/month)

$\begin{array}{lrlllrlcll}<R M 2 K & 155 & (73.8) & 54 & (34.8) & 101 & (65.2) & 0.99 & (0.52,1.88) & 0.969 \\ \geq R M 2 K & 55 & (26.2) & 19 & (34.5) & 36 & (65.5) & 1 & & \end{array}$


1. Diagnosis of ACS

$\begin{array}{lrllllllll}\begin{array}{l}\text { Unstable } \\ \text { angina }\end{array} & 105 & (50.0) & 43 & (41.0) & 62 & (59.0) & 1 & & 0.171 \\ \text { NSTEMI } & 50 & (23.8) & 14 & (28.0) & 36 & (72.0) & 1.78 & (0.86,3.70) & \\ \text { STEMI } & 55 & (26.2) & 16 & (29.1) & 39 & (70.9) & 1.69 & (0.84,3.40) & \end{array}$

2. Number of types of behavioural change

$\begin{array}{lrllllllll}\text { Up to } 3 & 99 & (47.1) & 55 & (55.6) & 44 & (44.4) & 1 & & <0.001^{*} \\ \text { 4 \& more } & 111 & (52.9) & 18 & (16.2) & 93 & (83.8) & 6.46 & (3.40,12.27)\end{array}$

3. Smoker status

$\begin{array}{llllllllll}\begin{array}{l}\text { Quitters \& } \\ \text { non-smokers }\end{array} & 181 & (86.2) & 72 & (39.8) & 109 & (60.2) & 1 & & <0.001^{*} \\ \begin{array}{l}\text { Active } \\ \text { smokers }\end{array} & 29 & (13.8) & 1 & (3.4) & 28 & (96.6) & 18.50 & (2.46,138.97) & \end{array}$

4. Alcoholic drinking status

$\begin{array}{lrlrlrlrlr}\text { Still drink } & 27 & (12.9) & 4 & (14.8) & 23 & (85.2) & 3.57 & (1.18,10.81) & 0.056 \\ \text { Quit drinking } & 16 & (7.6) & 5 & (31.2) & 11 & (68.8) & 1.37 & (0.45,4.12) & \\ \text { Non-drinker } & 167 & (79.5) & 64 & (38.3) & 103 & (61.7) & 1 & \end{array}$

${ }^{*}$ Adherence status refers to averaged sum of adherence scores. Suboptimal adherence $=$ adherence score $<5$; optimal adherence $=$ adherence score $\geq 5$.

‡ Minority ethnic was excluded from analysis

${ }^{*} p$ value $<0.05$ 
Table 4 Factors associated with the risk of suboptimal adherence among patients within a year following acute coronary syndrome

\begin{tabular}{|c|c|c|c|c|c|}
\hline \multirow[b]{2}{*}{ Factors } & & \multicolumn{2}{|l|}{ Unadjusted } & \multicolumn{2}{|l|}{ Adjusted $\neq$} \\
\hline & & Odds ratio & $(95 \% \mathrm{Cl})$ & Odds ratio & $(95 \% \mathrm{Cl})$ \\
\hline \multirow{2}{*}{$\begin{array}{l}\text { Number of } \\
\text { types of } \\
\text { behavioural } \\
\text { change }\end{array}$} & Up to 3 & 1 & & 1 & \\
\hline & $4 \&$ more & 6.46 & $(3.40,12.27)$ & 6.71 & $(3.38,13.35)$ \\
\hline \multirow[t]{2}{*}{ Smoking status } & Non smoking & 1 & & 1 & \\
\hline & Active smoking & 18.50 & $(2.46,138.97)$ & 24.41 & $(2.99,199.36)$ \\
\hline \multirow[t]{3}{*}{ Major race } & Malay & 1.38 & $(0.71,2.71)$ & 1.67 & $(0.77,3.63)$ \\
\hline & Chinese & 0.60 & $(0.29,1.26)$ & 0.63 & $(0.27,1.541)$ \\
\hline & Indian & 1 & & 1 & \\
\hline
\end{tabular}

